\title{
Antimicrobial resistance of Vibrio cholerae from sub-Saharan Africa: A systematic review
}

\begin{tabular}{|c|c|}
\hline $\begin{array}{l}\text { Authors: } \\
\text { Yahaya Mohar } \\
\text { Aaron O. Abo } \\
\text { Iruka N. Okek } \\
\text { Adebola T. Ola }\end{array}$ & 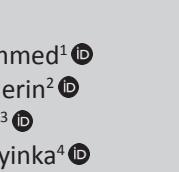 \\
\hline $\begin{array}{l}\text { Affiliations: } \\
{ }^{1} \text { Department } \\
\text { Microbiology } \\
\text { Parasitology, } \\
\text { Clinical Scienc } \\
\text { Health Scienc } \\
\text { Danfodiyo Un } \\
\text { Nigeria }\end{array}$ & $\begin{array}{l}\text { f Medical } \\
\text { and } \\
\text { aculty of Basic } \\
\text { es, College of } \\
\text { s, Usmanu } \\
\text { versity, Sokoto, }\end{array}$ \\
\hline $\begin{array}{l}\text { 2Department } \\
\text { Microbiology } \\
\text { Parasitology, C } \\
\text { Health Science } \\
\text { Awolowo Univ } \\
\text { Nigeria }\end{array}$ & $\begin{array}{l}\text { f Medical } \\
\text { and } \\
\text { ollege of } \\
\text { s, Obafemi } \\
\text { ersity, lle-Ife, }\end{array}$ \\
\hline $\begin{array}{l}{ }^{3} \text { Department } \\
\text { Pharmaceutic } \\
\text { Faculty of Pha } \\
\text { University of I } \\
\text { Nigeria }\end{array}$ & $\begin{array}{l}\text { f } \\
\text { rmacy, } \\
\text { padan, Ibadan, }\end{array}$ \\
\hline $\begin{array}{l}{ }^{4} \text { Department } \\
\text { Microbiology } \\
\text { Parasitology, F } \\
\text { Medicine, Ahn } \\
\text { University, Zar }\end{array}$ & $\begin{array}{l}\text { f Medical } \\
\text { nd } \\
\text { aculty of } \\
\text { nadu Bello } \\
\text { ia, Nigeria }\end{array}$ \\
\hline $\begin{array}{l}\text { Correspondin } \\
\text { Yahaya Mohar } \\
\text { yahyakt@yaho }\end{array}$ & $\begin{array}{l}\text { author: } \\
\text { nmed, } \\
\text { o.com }\end{array}$ \\
\hline $\begin{array}{l}\text { Dates: } \\
\text { Received: } 30 \mathrm{~J} \\
\text { Accepted: } 27 \\
\text { Published: } 06\end{array}$ & $\begin{array}{l}\text { an. } 2018 \\
\text { ept. } 2018 \\
\text { Dec. } 2018\end{array}$ \\
\hline $\begin{array}{l}\text { How to cite th } \\
\text { Mohammed Y, } \\
\text { Okeke IN, Olay } \\
\text { Antimicrobial } \\
\text { of Vibrio chole } \\
\text { sub-Saharan A } \\
\text { systematic rev } \\
\text { Med. 2018;7(2 } \\
\text { https://doi.org } \\
\text { v7i2.778 }\end{array}$ & $\begin{array}{l}\text { is article: } \\
\text { Aboderin AO, } \\
\text { inka AT. } \\
\text { esistance } \\
\text { rae from } \\
\text { frica: A } \\
\text { iew. Afr J Lab } \\
\text { ), a778. } \\
\text { /10.4102/ajlm. }\end{array}$ \\
\hline Read online: & \\
\hline 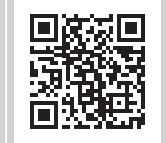 & $\begin{array}{l}\text { Scan this QR } \\
\text { code with your } \\
\text { smart phone or } \\
\text { mobile device } \\
\text { to read online. }\end{array}$ \\
\hline
\end{tabular}

Authors:

Iruka N. Okeke ${ }^{3}$ (D)

Adebola T. Olayinka ${ }^{4}$

Affiliations:

Microbiology and

Parasitology, Faculty of Basic

Clinical Sciences, College of

Health Sciences, Usmanu

Nigeria

${ }^{2}$ Department of Medica

Microbiology and

Health Sciences, Obafemi

Awolowo University, Ile-Ife,

Faculty of Pharmacy,

University of Ibadan, Ibadan,

${ }^{4}$ Department of Medical

Microbiology and

Parasitology, Faculty of

Medicine, Ahmadu Bello

Yahaya Mohammed,

Accepted: 27 Sept. 2018

Okeke IN, Olayinka AT.

Antimicrobial resistance

of Vibrio cholerae from

sub-Saharan Africa: A

Med. 2018:7(2), a778.

https://doi.org/10.4102/ajlm.

v7i2.778

mobile device

to read online.
Background: The World Health Assembly adopted the Global Action Plan on Antimicrobial Resistance, which includes improving the knowledge base through surveillance and research. Noteworthily, the World Health Organization has advocated a Global Antimicrobial Resistance Surveillance System to address the plan's surveillance objective, with most African countries enrolling in or after 2017.

Aim: The aim of this article was to review prior data on antimicrobial resistance of Vibrio cholerae from sub-Saharan Africa with a view for future control and intervention strategies.

Methods: We used the Preferred Reporting Items for Systematic Review and Meta-Analysis (or 'PRISMA') guidelines to search the PubMed and African Journals Online databases, as well as additional articles provided by the Nigeria Centre for Disease Control, for articles reporting on the antibiotic susceptibility of $V$. cholerae between January 2000 and December 2017.

Results: We identified 340 publications, of which only 25 (reporting from 16 countries within the sub-Saharan African region) were eligible. The majority $(20 ; 80.0 \%)$ of the cholera toxigenic $V$. cholerae isolates were of the serogroup $\mathrm{O} 1$ of the El Tor biotype with Ogawa and Inaba serotypes predominating. Resistance was predominantly documented to trimethoprimsulphamethoxazole ( $50 \%$ of the studies), ampicillin ( $43.3 \%$ of the studies), chloramphenicol (43.3\% of the studies) and streptomycin (30\% of the studies). Resistance mechanisms were reported in $40 \%$ of the studies.

Conclusion: Our results demonstrate a documented antimicrobial resistance of $V$. cholerae to multiple antibiotic classes, including cell wall active agents and antimetabolites with evidence of phenotypic/genotypic resistance to fluoroquinolones.

\section{Introduction}

Vibrio cholerae are Gram-negative and curved bacilli. Certain members of this species are associated with a severe acute watery diarrhoea that is the most distinctive sign of a clinical condition called cholera. ${ }^{1}$ There exist numerous $V$. cholerae serogroups, but the $\mathrm{O} 1$ and $\mathrm{O} 139$ strains stand out as the major agents for the major outbreaks of cholera globally. The serogroup O139 is majorly restricted to some parts of Asia; however, serogroup O1 V. cholerae, further subdivided into the El Tor and classical biotypes, are distributed worldwide. ${ }^{2}$

The $V$. cholerae $\mathrm{O} 1 \mathrm{El}$ Tor biotype was responsible for the seventh cholera pandemic, which started in Indonesia and spread rapidly to Bangladesh, India, Iran and Iraq. ${ }^{3}$ Cholera was imported to Africa in the 1970s from these countries during this seventh pandemic. It entered from West Africa from where it spread to East, Central and South Africa. ${ }^{4}$

$V$. cholerae virulence and drug resistance evolved during the course of the seventh pandemic and a new variant cholera biotype emerged. ${ }^{2}$ This variant is called the 'hybrid' or 'atypical' biotype and it has mixed markers of the classical and El Tor biotypes. Hybrid V. cholerae have the El Tor biotype, but with the non-El Tor $c t x B$ toxigenic allele. This atypical El Tor biotype is associated with higher virulence and more widespread antibiotic resistance. ${ }^{2}$

Atypical $V$. cholerae carry mobile genetic elements like the integrative/conjugative elements (ICEs), which are capable of self-transfer and integration into host chromosomes, facilitating rapid spread and stable acquisition. ${ }^{5}$

Recently, the occurrence of new variant pathogenic strains of $V$. cholerae has been attributed to new CTX prophage rearrangements. ${ }^{6}$ Resistant $V$. cholerae have disseminated globally and now threaten

Copyright: (C) 2018. The Authors. Licensee: AOSIS. This work is licensed under the Creative Commons Attribution License. 
the effective treatment and control of cholera, especially in the low and middle-income countries. ${ }^{1,5}$ Recent evidence suggests that cholera is exacting a very high burden on the African continent in this era. ${ }^{6}$ However, few data are available about the nature and extent of outbreaks or the properties of strains. ${ }^{7}$ Multi-country or global studies generally have less input from Africa. ${ }^{8}$

Upon commissioning from the Nigeria Centre for Disease Control (NCDC), we set out to review data on the antimicrobial resistance of $V$. cholerae from publications done in sub-Saharan Africa, in order to provide evidence that may serve as a yardstick for future control programmes and interventions.

\section{Methodology Overview of study protocol}

This systematic review was done using the Preferred Reporting Items for Systematic Reviews and Meta-Analysis (or 'PRISMA') guidelines. ${ }^{9}$ The protocol for the study was developed in conjunction with the NCDC panel of experts and a more detailed version of the protocol is available on request.

\section{Search strategy}

We searched Medline using PubMed for articles published in English between 01 January 2000 and 31 December 2017 with the search terms 'antimicrobial resistance', 'antibiotic resistance', 'Vibrio cholerae' and the names of the individual countries of sub-Saharan Africa. Additional searches were done in the African Journals Online database, using an additional search term of 'antimicrobial susceptibility'. We also scanned a list of articles obtained from the NCDC to select eligible articles that conformed with our search terms.

\section{Study selection criteria}

Articles were included for this review provided they reported on the antimicrobial susceptibility profile of $V$. cholerae isolates from clinical specimens in sub-Saharan Africa and were published between January 2000 and December 2017. We included articles irrespective of whether the isolates were obtained as part of an outbreak investigation or from a hospital-based site using cross-sectional survey, provided they were from human specimens.

\section{Selection procedure}

The titles and abstracts of all search results were listed and were thereafter reviewed to identify papers for full text review. The selection procedure is outlined in Figure 1. Fortyfive papers were excluded, because all attempts to secure full text versions were unsuccessful. Names of authors from articles were not blinded before or after the full text review. We used predetermined inclusion and exclusion criteria to select papers for full review. Papers selected for full review after abstract review were retrieved as full manuscript papers through PubMed, HINARI, from the NCDC or by personal communication with the corresponding authors. Seventy-six

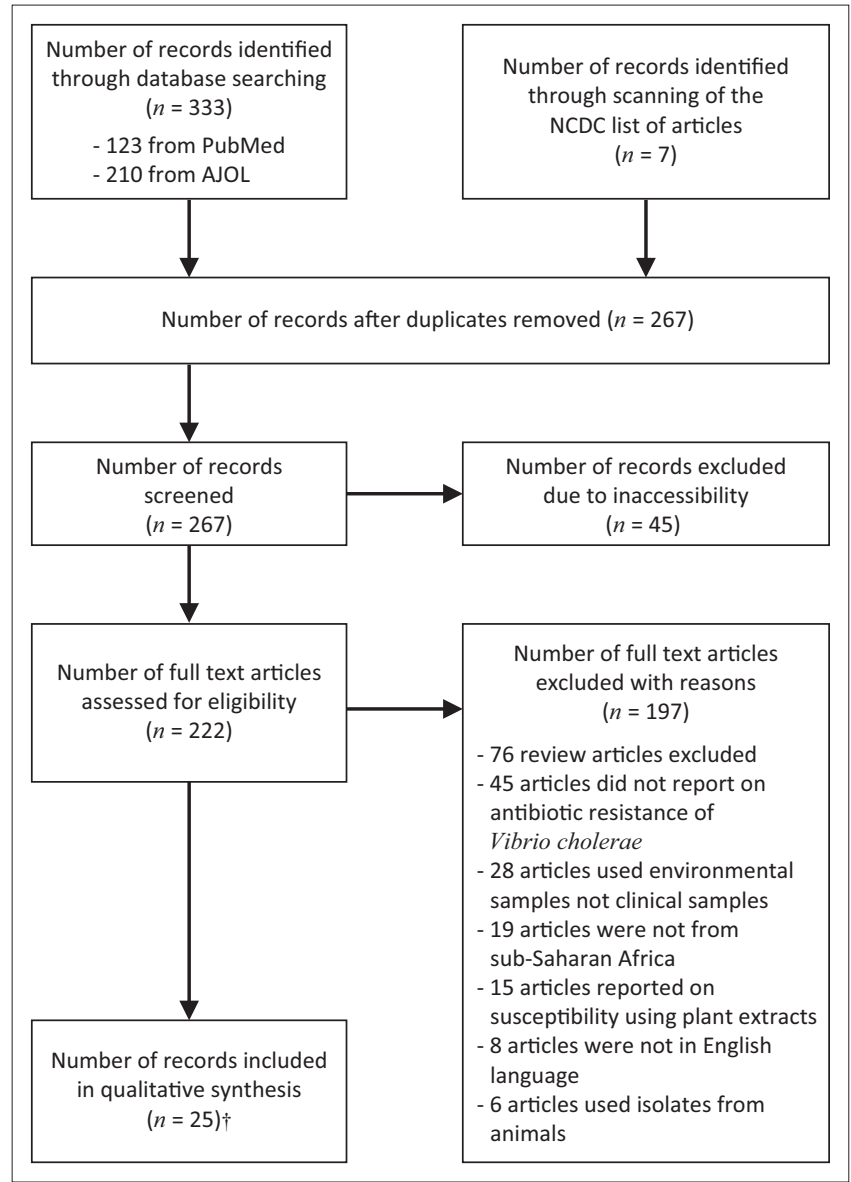

$\dagger$, One article reported from five countries of sub-Saharan Africa and the study was divided into five for convenience thereby bringing the number of articles to 29 .

FIGURE 1: Summary of study selection procedure.

review articles were excluded, and 45 papers did not report on the susceptibility pattern of $V$. cholerae and were also excluded. Twenty-eight papers were on environmental samples; hence, they were excluded. Nineteen articles were not from sub-Saharan Africa and 15 articles evaluated susceptibility to plant extracts and, consequently, they were all excluded. Eight articles were in French and six articles used isolates from animal sources and they were all excluded.

\section{Data extraction}

A database was created in which the study name, study period, susceptibility pattern, biochemical properties, genes and virulence factors of the $V$. cholerae isolates from countries of sub-Saharan Africa were recorded where applicable (Table 1). We could not adequately carry out a quantitative study, because most of the susceptibility patterns of the isolates were not recorded in actual numerical values. Most of the studies also did not report on the quality control procedure they used and some of the studies relied only on molecular detection of resistance genes.

\section{Attempt to reduce bias}

An attempt to reduce bias within studies and between individual studies was done. The review was also conducted in a group with materials, articles and the papers doublechecked by at least two members of the group. 
TABLE 1: Characterisation of eligible articles that sought resistance of Vibrio cholerae from countries in sub-Saharan Africa.

\begin{tabular}{|c|c|c|c|c|c|c|c|c|c|}
\hline $\begin{array}{l}\text { Study } \\
\text { number }\end{array}$ & Study name & Year & Ref & Study location & $\begin{array}{c}\text { Proportion of } \\
\text { resistance to cell } \\
\text { wall active agents } \\
(\%)\end{array}$ & $\begin{array}{c}\text { Proportion of } \\
\text { resistance to } \\
\text { fluoroquinolones } \\
(\%)\end{array}$ & $\begin{array}{c}\text { Proportion of } \\
\text { resistance to nucleic } \\
\text { acid inhibitors } \\
(\%)\end{array}$ & $\begin{array}{c}\text { Proportion of } \\
\text { resistance to protein } \\
\text { synthesis inhibitors; } \\
\text { 30S (\%) }\end{array}$ & $\begin{array}{c}\text { Proportion of } \\
\text { resistance to } \\
\text { protein synthesis; } \\
50 \mathrm{~S}(\%)\end{array}$ \\
\hline 1 & Ceccarelli D & 2011 & 6 & Angola & 100 & 100 & 100 & 100 & 100 \\
\hline 2 & Kaas RS & 2010 & 10 & Chad & NA & 100 & 100 & 100 & 100 \\
\hline 3 & Kacou-N'douba A & 2012 & 11 & Cote d'Ivoire & 25 & 0 & 100 & 0 & 100 \\
\hline 4 & Smith $\mathrm{AM}_{\dagger}^{\dagger}$ & 2015 & 12 & Cote d'Ivoire & 0 & 50 & 100 & 0 & 100 \\
\hline 5 & Miwanda B & 2015 & 13 & DRC & NA & 0 & 100 & NA & 100 \\
\hline 6 & Smith $\mathrm{AM} \dagger$ & 2015 & 12 & DRC & 0 & 50 & 100 & 25 & 0 \\
\hline 7 & Opintan JA & 2008 & 15 & Ghana & 100 & 50 & 100 & 100 & 100 \\
\hline 8 & Eibach D & 2016 & 14 & Ghana & 100 & 25 & 100 & 0 & 0 \\
\hline 9 & Dalsgaard A & 2000 & 4 & Guinea Bissau & 100 & NA & 100 & 100 & 100 \\
\hline 10 & Smith $\mathrm{AM} \dagger$ & 2015 & 12 & Guinea Bissau & 100 & 0 & 100 & 0 & 100 \\
\hline 11 & Urassa WK & 2000 & 16 & Kenya & 100 & 100 & 0 & 100 & 100 \\
\hline 12 & Scrascia M & 2006 & 17 & Kenya & NA & 0 & 100 & 0 & 100 \\
\hline 13 & Sang WK & 2012 & 18 & Kenya & 100 & 50 & NA & 0 & 100 \\
\hline 14 & Dromigny J-A & 2002 & 19 & Madagascar & 100 & 100 & NA & 100 & NA \\
\hline 15 & Smith $\mathrm{AM} \dagger$ & 2015 & 12 & Mozambique & 100 & 50 & 100 & 100 & 100 \\
\hline 16 & Dengo-Baloi LC & 2007 & 20 & Mozambique & 100 & 50 & 100 & 50 & 50 \\
\hline 17 & Smith AM & 2007 & 21 & Namibia & 0 & 0 & 100 & 0 & 0 \\
\hline 18 & Okeke IN & 2001 & 22 & Nigeria & NA & NA & 100 & 0 & 100 \\
\hline 19 & Opajobi SO & 2004 & 23 & Nigeria & 100 & 0 & NA & 0 & 50 \\
\hline 20 & Quilici M-L & 2010 & 24 & Nigeria & 50 & 100 & 100 & 0 & 25 \\
\hline 21 & Marin MA 2013 & 2013 & 25 & Nigeria & NA & 100 & 100 & NA & 25 \\
\hline 22 & Marin MA 2014 & 2014 & 26 & Nigeria & NA & 0 & 100 & 0 & 25 \\
\hline 23 & Sambe-Ba B & 2017 & 30 & Senegal & NA & NA & 100 & 0 & NA \\
\hline 24 & Ismail H & 2008 & 31 & South Africa & 100 & 50 & 100 & 100 & 50 \\
\hline 25 & Moyo SJ & 2011 & 32 & Tanzania & 100 & 0 & 0 & 100 & 100 \\
\hline 26 & Mercy N & 2014 & 33 & Tanzania & NA & 0 & 100 & 0 & 0 \\
\hline 27 & Smith $\mathrm{AM} \dagger$ & 2015 & 12 & Togo & 0 & 50 & 100 & 0 & 0 \\
\hline 28 & Mwansa JCL & 2006 & 34 & Zambia & NA & NA & NA & 100 & NA \\
\hline 29 & Chiyangi H & 2017 & 35 & Zambia & 0 & 75 & 100 & 100 & 0 \\
\hline
\end{tabular}

$\dagger$, This article reported from five countries of sub-Saharan Africa (Reference 12).

Ref, reference number from this study; DRC, Democratic Republic of the Congo; NA, not available.

\section{Analysis approach}

The extracted data were reported as outlined by the authors using the susceptibility categorisation of the pathogens into sensitive, intermediate and resistant. We reported on the biochemical characteristics of the $V$. cholerae in terms of serogroup, biotype and serotype. We also reported on the clinical diagnosis for isolates in studies where diagnosis was stated. We also highlighted the use of molecular methods, genotyping or virulence features for the characterisation of isolates wherever such data were available.

\section{Results}

\section{General characteristics of the studies included in the analysis}

Our search generated 267 articles after removal of duplicates. During abstract review, we excluded 242 articles, because they did not meet our inclusion criteria. Twenty-five articles were included in the final analysis.

One article reported resistance of $V$. cholerae from five subSaharan African countries and was therefore divided into five for convenience. In all, the articles obtained reported on 16 of the 47 countries within the sub-Saharan African region. One study (3.4\% for each) was obtained from each of the following countries: Angola, Chad, Madagascar, Namibia, Senegal, South Africa and Togo. Two studies (6.9\% for each) were from each of Cote d'Ivoire, Democratic Republic of the Congo, Ghana, Guinea Bissau, Mozambique, Tanzania and Zambia. Three $(10.3 \%)$ studies were from Kenya and five (17.2\%) were from Nigeria.

Twenty-four (82.8\%) of the studies reported serogroup O1 as the only serogroup, while two $(6.9 \%)$ studies reported the O1 serogroup coexisting with the non-O1/non-O139 serogroup, but even in those studies the $\mathrm{O} 1$ serogroup dominated. Three $(10.3 \%)$ studies did not report on the serogroup status. None of the studies reported the O139 serogroup from any country in the region of sub-Saharan Africa.

Twenty two (75.9\%) studies reported the El Tor biotype, while one (3.4\%) study reported the existence of the El Tor and the atypical El Tor biotype. Six (20.7\%) of the studies did not biotype their isolates. There was no report of the classical biotype from any of the studies.

Eight $(27.6 \%)$ studies reported the Ogawa serotype as the predominant serotype, three (10.3\%) studies reported on Inaba existing alone and six (20.7\%) reported the Ogawa/ Inaba coexisting together. The coexistence of Inaba/Ogawa/ 
Hikojima was reported from one (3.4\%) study. Eleven (37.9\%) of the studies did not report on any of the serotypes.

Seventeen studies detected or confirmed cholera toxin and toxin-co-regulated pilus genes $(\operatorname{ct} x B, \operatorname{ct} x A$ and $t c p A)$.

Table 1 shows the characteristics of eligible articles that investigated resistance of $V$. cholerae from sub-Saharan Africa. Resistance was documented to trimethoprimsulphamethoxazole (50\% of the studies), ampicillin (43.3\%), chloramphenicol $(43.3 \%)$, streptomycin $(30 \%)$, nalidixic acid $(30 \%)$, nitrofurantoin $(26.7 \%)$, ceftriaxone $(20 \%)$, spectinomycin $(10 \%)$, sulfonamide $(6.7 \%)$, penicillin G $(6.7 \%)$ and cloxacillin (3.3\%). The antibiotics to which susceptible strains were reported were: tetracycline $(46.7 \%$ of the studies), amoxicilin/clavulanic acid (6.7\%), florfenicol (3.3\%), azithromycin (3.3\%), imipenem $(3.3 \%)$, ciprofloxacin $(3.3 \%)$, ofloxacin $(3.3 \%)$ and erythromycin $(3.3 \%)$.

Mutations in antibiotic resistance determinants (gyrA, parC, floR, strA, and $\operatorname{str} B)$ were detected in nine (31.1\%) of the studies, while twenty (68.9\%) studies did not conduct genotypic studies on the isolates.

The ICEVChAng2 and ICEVChInd5 were reported from seven $(24.1 \%)$ of the studies while the other twenty-two $(75.9 \%)$ studies did not perform this genotypic analysis.

\section{Summary of the resistance studies on the Vibrio cholerae isolates from the various studies}

The average prevalence of resistance to cell wall active agents by the $V$. cholerae organisms from 20 studies was $68.8 \%$ (100$0 \%$ ). However, 25 studies reported on the resistance to fluoroquinolones with their total average of $44.0 \%$ (100-0\%), while the average prevalence of resistance to inhibitors of nucleic acid, predominantly the sulphonamide and cotrimozaxole, was $92.0 \%$ from 25 studies (Table 1 ).

Twenty-seven studies reported 43.5\% (100-0\%) prevalence of resistance to protein synthesis inhibitors of $30 \mathrm{~S}$ subunit, while the average prevalence of resistance to protein synthesis inhibitors of $50 \mathrm{~S}$ subunit (Table 1) was $62.5 \%$ (100-0\%) from 26 eligible studies.

\section{Specific characteristics of the studies included in the analysis}

In Angola, Ceccarelli et al. performed a retrospective study on $V$. cholerae $\mathrm{O} 1 \mathrm{El}$ Tor strains responsible for the 2006 outbreak. The isolates were resistant to all the major groups of antimicrobials tested and they demonstrated the appearance of a novel $V$. cholerae epidemic variant in Africa with a new СТХФ arrangement previously described only in the Indian subcontinent. $^{6}$ Kaas et al. investigated the 2010/2011 $V$. cholerae outbreak in Lake Chad basin around Cameroon. The outbreak strains were resistant to all the antimicrobials tested and, in addition, possessed the integrative conjugative element ICEVchInd5. This is said to be clonal and clustered, distant from the other African strains. ${ }^{10}$
Kacou-N'douba et al. documented resistance to chlorampenicol and cotrimoxazole during a cholera epidemic in 2011 from Cote d'Ivoire. ${ }^{11}$

Smith and colleagues characterised $V$. cholerae $\mathrm{O} 1$ from Cote d'Ivoire, Democratic Republic of the Congo, Guinea Bissau, Mozambique and Namibia. All the isolates were of Ogawa serotype and positive for the $\operatorname{ct} x A$ gene. There was generalised resistance to nalidixic acid, chloramphenicol and cotrimoxazole in all isolates from the five countries. ${ }^{12}$ In Democratic Republic of the Congo, Miwanda et al. documented resistance to cotrimoxazole, erythromycin and chloramphenicol. However, no resistance to fluoroquinolones was reported from this study. ${ }^{13}$ In two separate studies from Ghana, Eibach et al. ${ }^{14}$ and Opintan et al. ${ }^{15}$ documented resistance to trimethoprimsulphamethoxazole, ampicillin and nalidixic acid. Dalsgaard and colleagues ${ }^{4}$ from Guinea Bissau demonstrated resistance to ampicillin, aminoglycosides, cotrimoxazole and tetracycline. Only colistin remained effective from their study. They also demonstrated that resistant isolates possessed a multiresistance transmissible plasmid that encoded trimethoprim (dhfrXII) and aminoglycoside resistance (ant(3")-1a).

In Kenya, Urassa et al. ${ }^{16}$ documented resistance to ciprofloxacin, tetracycline, ampicillin, erythromycin and chloramphenicol by $V$. cholerae during two separate outbreaks. ${ }^{16}$ Another study from Kenya by Scrascia et al. ${ }^{17}$ showed resistance of $V$. cholerae to chloramphenicol, streptomycin and cotrimoxazole. ${ }^{17}$

Sang and colleagues $^{18}$ in Kenya were able to demonstrate resistance to ciprofloxacin, tetracycline, ampicillin, erythromycin and chloramphenicol among $V$. cholerae isolates. ${ }^{18}$ Dromigny and colleagues ${ }^{19}$ conducted a study in Madagascar in 2002 among $V$. cholerae isolates and documented resistance to tetracycline, ampicillin, nalidixic acid and nitrofurantoin. ${ }^{19}$ Dengo-Baloi et al..$^{20}$ performed a study in Mozambique to determine the antibiotic resistance patterns of $V$. cholerae $\mathrm{O} 1$ Ogawa. The isolates were resistant to ampicillin, azithromycin, sulphamethoxazole, nalidixic acid and nitrofurantoin. Genes for cholera toxin $(c t x A, r s t R 2, t c p A)$ and the virulence factors of ICEVChBan 9 and ICEVchInd5 were elaborated..$^{20}$

Smith from Namibia ${ }^{21}$ characterised isolates of $V$. cholerae from a 2006/2007 outbreak and the isolates were all resistant to trimethoprim, sulphamethoxazole and streptomycin. The isolates possessing either the SfiI or NotI digestion sites were further analysed using advanced molecular techniques and it was demonstrated that they all have the same origin. ${ }^{21}$ Okeke and colleagues ${ }^{22}$ investigated an outbreak of acute gastroenteritis from Niger state, north-central Nigeria, where eight $V$. cholerae organisms were isolated. They all had the O1-serogroup and El Tor biotype. All of them were sensitive to tetracycline but resistant to trimethoprim, sulphonamide, spectinomycin and chloramphenicol. ${ }^{22}$

Opajobi et al. ${ }^{23}$ detected 34 strains of $V$. cholerae in Jos University Teaching Hospital over a one-year period. 
They were all of the O1 serogroup, El Tor biotype and Inaba serotype. They were all resistant to chloramphenicol, ampicillin, cloxacillin and penicillin $G$, but sensitive to tetracycline, ofloxacin and erythromycin. ${ }^{23}$

A study done by Quilici et al. ${ }^{24}$ using the V. cholerae isolates from the September/October 2009 outbreak of acute watery diarrhoea in north-eastern Nigeria and northern Cameroon implicated the serogroup O1 of the El Tor biotype and Ogawa serotype as the causative serotypes. The toxigenic genes of $\operatorname{ct} x A$ and $\operatorname{ct} x B$ were elaborated, in addition to detected mutations in the genes responsible for quinolone resistance. The $c t x B$ gene was similar to the one detected in India. All of them were resistant to trimethoprim-sulphamethoxazole, ciprofloxacin, sulphonamide and nalidixic acid. All the isolates were resistant to tetracycline, but moderately susceptible to chloramphenicol and ampicillin. ${ }^{24}$ In 2013, Marin and colleagues ${ }^{25}$ described $V$. cholerae that were isolated from cases of acute watery diarrhoea outbreaks in Nigeria from 2009 to 2010. They reported that these toxigenic $V$. cholerae isolates were mostly of $\mathrm{O} 1$ serotype, and that atypical El Tor strains with the integrative conjugative element (ICE) of the sulfamethoxazole and trimethoprim (SXT) element, gyrA, cholera toxin (CTX) phage and cytidine triphosphate (CTP) synthetase clusters showed reduced susceptibility to ciprofloxacin and chloramphenicol.

Another study by Marin et al. ${ }^{26}$ in 2014 characterised the whole genome of 13 strains of $V$. cholerae that were obtained from the 2010 outbreak. They all harboured an ICE (ICEVchNig1) that was characterised and shown to possess genes for trimethoprim, sulfamethoxazole, streptomycin and chloramphenicol resistance. They were found to have the same gene content and gene order with similar elements detected over 20 years ago in Haiti, ${ }^{27}$ Angola $^{6}$ and Bangladesh..$^{28}$ Dutilh and colleagues ${ }^{29}$ used an innovative model to characterise the genomic variation of microbial genome with specific reference to $V$. cholerae isolates obtained worldwide with Nigeria inclusive. They were able to outline mobile functions of phages, prophages, transposable elements, and plasmids. They constructed a phylogenetic tree that revealed that the $V$. cholerae strain isolated in 2010 from Nigeria was closely related to strains already circulating in Nepal and Haiti. ${ }^{29}$

In Senegal, the study by Sambe-Ba et al. ${ }^{30}$ identified atypical El Tor V. cholerae O1 Ogawa that were resistant to streptomycin and cotrimoxazole. Ismail and colleagues ${ }^{31}$ from South Africa characterised a multi-resistant $V$. cholerae with resistance to ampicillin, cotrimoxazole, nalidixic acid, tetracycline, kanamycin and streptomycin. The isolates were positive for the SXT element, had quinolone resistance-determining mutations in the genes encoding GyrA (Ser83-Ile) and ParC (Ser85-Leu) and produced TEM-63- $\beta$-lactamase. ${ }^{31}$

A study in Tanzania by Moyo et al. ${ }^{32}$ documented resistance to ampicillin, amoxicillin-clavulanate, erythromycin, chloramphenicol, tetracycline, gentamicin and cephalothin. Another study in Tanzania by Mercy et al. $^{33}$ identified resistance of $V$. cholerae to furazoline, trimethoprimsulphamethoxazole, polymyxin-B and streptomycin. The cholera virulence determinant genes $c t x A, t c p A, \operatorname{ct} x B$ and $r t x C$ were also elaborated. In Zambia, Mwansa and colleagues ${ }^{34}$ documented resistance of $V$. cholerae to trimethoprim, sulphamethoxazole, tetracycline and furazolidine. The cholera toxin and the virulence genes $c t x A, r s t R 2, r f b O 1$ and $t c p A$ were also elaborated. ${ }^{34}$ Chiyangi et al., ${ }^{35}$ also from Zambia, detected resistance to cotrimoxazole, nalidixic acid and nitrofurantoin. ${ }^{35}$

\section{Discussion}

Cholera outbreaks have been ongoing within sub-Saharan African countries for the past four decades. Unfortunately, the specific strains responsible and their antibiotic resistance patterns are not well studied and elucidated. ${ }^{36}$ This consequently impacts negatively on the control programmes for cholera across the continent.

Despite our extensive database searches, we could only find a few articles that exclusively met our inclusion criteria of reporting antibiotic resistance profiles of $V$. cholerae from subSaharan Africa. This reflects a worrisome neglect of research on $V$. cholerae resistance trends from sub-Saharan Africa, despite the high prevalence of $V$. cholerae and its almost seasonal occurrence. ${ }^{29,37}$

We were able to retrieve some of the identified full text reviews from major databases by personally contacting the corresponding authors, which we recommend for researchers from developing countries like ours. There is a changing pattern of Vibrio cholerae serogroups and biotypes responsible for cholera outbreaks worldwide. ${ }^{2}$ During the seventh pandemic, the typical El Tor strain was responsible for outbreaks in Asia, Caribbean countries and Africa. However, studies have now highlighted the fact that the multi-drug resistant atypical El Tor and non-O1/non-O139 V. cholerae strains are the major drivers worldwide with sub-Saharan Africa included. ${ }^{2}$ The study done by Marin et al. ${ }^{22}$ signifies that the $2009 / 2010$ outbreaks were caused by a highly multidrug resistant atypical El Tor strain carrying major virulence determinants..$^{22}$

Our review revealed only $V$. cholerae isolates of the $\mathrm{O} 1$ and the non-O1/non-O139 serogroup with absence of the O139 serogroup from sub-Saharan Africa. This is consistent with literature evidence that reflects the occurrence of the $V$. cholerae $\mathrm{O} 139$ to be mostly restricted to Bangladesh and parts of India. ${ }^{37}$

None of the studies in our review detected the 'classical' biotype of $V$. cholerae. The classical biotype has ceased to be implicated in cholera outbreaks globally, has been replaced by the El Tor since after the sixth pandemic and is now mostly restricted to Bangladesh. ${ }^{38}$

The stand-alone existence of the Hikojima serotype was not detected by any of the studies from our review. This is not 
surprising as the Hikojima serotype is rare and contains all the major antigens (A, B and C). One current hypothesis is that the Hikojima serotype is an unstable serotype that represents a transitional state between Ogawa to Inaba serotype. ${ }^{39}$

$V$. cholerae displayed an increasingly complex resistance phenotype to various antimicrobial drugs from our review. The majority of the studies we reviewed did not state the guidelines they followed in conducting the antimicrobial susceptibility testing; nevertheless, they reported variable levels of resistance to the fluoroquinolones. The existence of quinolone resistance-determining mutations in gyrA and parC in most of the isolates studied provides a genetic basis for fluoroquinolone resistance. The isolated Vibrio cholerae strains that harboured the fluoroquinolone resistant genes were resistant to multiple antimicrobial agents, which has important implications for the antimicrobial-based epidemic control strategies that are still the mainstay within countries in sub-Saharan Africa. ${ }^{40}$

An increasing trend of resistance to cotrimoxazole was observed from many studies. Kacou- $\mathrm{N}^{\prime}$ douba ${ }^{11}$ and Smith et al. ${ }^{12}$ documented resistance to chloramphenicol and cotrimoxazole from their studies in Cote d'Ivoire, Democratic Republic of the Congo, Guinea Bissau, Mozambique and Namibia. ${ }^{11,12}$ This is worrisome, because, until now, cotrimoxazole was considered the drug of choice against $V$. cholerae.

This study provides support for the more recently advocated vaccine-based strategies, which have a better chance of reducing outbreak size and case fatality rates. As access to cholera vaccine stockpiles is dependent on laboratory confirmation of cholera, public health laboratory strengthening is essential. ${ }^{41}$

In Angola, Ceccarelli et al. demonstrated the appearance of a novel $V$. cholerae epidemic variant in Africa with a new CTXФ arrangement previously described only on the Indian subcontinent. ${ }^{6}$ Similarly, Quilici et al. ${ }^{24}$ identified a strain of $V$. cholerae from Nigeria with resistant $\operatorname{ct} x B$ clones that are similar to a strain identified earlier in India. This possibly indicates a trans-continental transmission of resistant organisms and this has implication for global health for appropriate international control. ${ }^{42}$

The finding of transferable resistance to almost all of the antibiotics commonly used to treat cholera was documented from many studies. Some of this was documented by Ceccarelli, ${ }^{1}$ Kaas, ${ }^{2}$ Dalsgaard ${ }^{4}$ and Ismail. ${ }^{31}$ This is of great public health concern and a cause of alarm for the continent.

This finding also highlights the need to develop Africa's capacity in terms of national reference laboratories, because the use of serotyping and bio-typing is inadequate for tracking the origin and clonality of $V$. cholerae isolates. Genotypic analysis, multi-locus sequence analysis, pulse field gel electrophoresis or whole genome sequence analyses are needed to track clonality. Unfortunately, these methods are more advanced and only available in a few reference laboratories within the continent. ${ }^{4}$

\section{Limitations}

The most appropriate pictorial representation for metaanalytic data is the forest plot. However, we could not construct one because the studies we included did not provide the component data that is essential for a forest plot.

\section{Conclusion}

Antimicrobial resistance exists among $V$. cholerae isolates from sub-Saharan Africa and includes the most feared fluoroquinolone resistance variety as well as resistance to the cell wall active agents and antimetabolites. The volume of research from countries in sub-Saharan Africa on antimicrobial resistance trends in $V$. cholerae needs to be expanded and better explored. Guidelines on antimicrobial chemotherapy and standardisation of antimicrobial susceptibility testing need to be strictly adhered to.

\section{Acknowledgements}

We thank the Nigeria Antimicrobial Resistance Technical group for review of an earlier version of this manuscript and we are grateful to Nigeria Centre for Disease Control for commissioning and supporting the research.

\section{Competing interests}

The authors declare that they have no financial or personal relationships that may have inappropriately influenced them in writing this article.

\section{Sources of support}

The study was supported by the Nigeria Centre for Disease Control, Abuja. The authors carried out the assignment as part of their routine work. I.N.O is a UK Medical Research Council and Department for International Developmentsupported African research leader.

\section{Authors' contributions}

Y.M. was the project leader, A.O.A., I.N.O. and A.T.O. were responsible for experimental and project design. Y.M. performed most of the experiments. A.O.A., I.N.O. and A.T.O. made conceptual contributions and performed some of the experiments. A.O.A., I.N.O and A.T.O. prepared the samples and calculations were performed by Y.M.

\section{References}

1. Salim A, Lan R, Reeves PR. Pathogenic clones. Emerg Infect Dis. 2005;11:17581760. https://doi.org/10.3201/eid1111.041170

2. Safa A, Nair GB, Kong RYC. Evolution of new variants of Vibrio cholerae 01. Trends Microbiol [serial online]. 2010 [cited 2017 Jan 25];18:46-54. Available from: http://www.ncbi.nlm.nih.gov/pubmed/19942436

3. WHO. Cholera outbreak-assessing the outbreak response and improving preparedness [homepage on the Internet]. Global Task Force on Cholera Control,
WHO/CDS/CPE/ZFK. 2004 [cited 2017 Jan 25]. Available from: www.who.int/ cholera 
4. Dalsgaard A, Forslund A, Petersen A, et al. Class 1 Integron-borne, multipleantibiotic resistance encoded by a 150-kilobase conjugative plasmid in epidemic Vibrio cholerae 01 strains isolated in Guinea-Bissau. J Clin Microbiol. Vibrio cholerae 01
2000;38:3774-3777.

5. Kitaoka M, Miyata ST, Unterweger D, Pukatzki S. Antibiotic resistance mechanisms of Vibrio cholerae. J Med Microbiol [serial online]. 2011 [cited 2017 Feb 04];60:397407. Available from: http://www.ncbi.nlm.nih.gov/pubmed/21252269

6. Ceccarelli D, Spagnoletti M, Bacciu D, Cappuccinelli P, Mauro MC. New Vibrio cholerae atypical El Tor variant emerged during the 2006 epidemic outbreak in Angola. BMC Microbiol. 2011;11:130. https://doi.org/10.1186/1471-2180-11-130

7. Mutreja A, Kim DW, Thomson NR, et al. Evidence for several waves of global transmission in the seventh cholera pandemic. Nature. 2011;477;462-465. https://doi.org/10.1038/nature10392

8. Mintz ED, Guerrant RL. A lion in our village - The unconscionable tragedy of cholera in Africa. N Engl J Med. 2009;360(11):1060-1063. https://doi.org/ 10.1056/NEJMp0810559

9. Moher D, Liberati A, Tetzlaff J, Altman DG. Preferred reporting items for systematic reviews and meta-analyses: The PRISMA statement. PLoS Med. 2009;6:7:e1000097. https://doi.org/10.1371/journal.pmed.1000097

10. Kaas RS, Ngandjio A, Nzouankeu A, et al. The Lake Chad Basin, an isolated and persistent reservoir of Vibrio cholerae 01: A genomic insight into the outbreak in Cameroon, 2010. PLoS One. 2016;11(5):e0155691. https://doi.org/10.1371/ journal.pone.0155691

11. Kacou-N'douba A, Blessa Anné JC, Okpo LS, Elogne-Kouamé C, Koffi S, Koffi V. Antimicrobial resistance of Vibrio cholerae $\mathrm{O} 1$ isolated during a cholera epidemic in 2011 in dry season in Cote d'lvoire. J Infect Dev Ctries. 2012;6(7):595-597. https://doi.org/10.3855/jidc.2001

12. Smith AM, Njanpop-Lafourcade B-M, Mengel MA, et al. Comparative characterization of Vibrio cholerae 01 from five sub-Saharan African countries using various phenotypic and genotypic techniques. PLoS One. using various phenotypic and genotypic techniques. PLoS
2015;10(11):e0142989. https://doi.org/10.1371/journal.pone.0142989

13. Miwanda B, Moore S, Muyembe J-J, Nguefack-Tsague G, Kabangwa IK, Ndjakani DY. Antimicrobial drug resistance of Vibrio cholerae, Democratic Republic of the Congo. Emerg Infect Dis. 2015;21(5):847. https://doi.org/10.3201/eid2105.141233

14. Eibach D, Herrera-León S, Gil H, Hogan B, Ehlkes L, Adjabeng M. Molecular epidemiology and antibiotic susceptibility of Vibrio cholerae associated with a large cholera outbreak in Ghana in 2014. PLoS Neglected Trop Dis [serial online]. 2016 [cited 2017 Jan 18]. Available from: https://doi.org/10.1371/journal. 2016 [cited

15. Opintan JA, Newman MJ, Nsiah-Poodoh OA, Okeke IN. Vibrio cholerae 01 from Accra, Ghana carrying a class 2 integron and the SXT element. J Antimicrob Accra, Ghana carrying a class 2 integron and the SXT element.
Chemother. 2008;62:929-933. https://doi.org/10.1093/jac/dkn334

16. Urassa WK, Mhando YB, Mhalu FS, Mgonja SJ. Antimicrobial susceptibility pattern of Vibrio Cholerae 01 strains during two cholera outbreaks in Dar Es Salaam, Tanzania. East Afr Med J. 2000;77(7):350-353.

17. Scrascia M, Maimone F, Mohamud KA, et al. Clonal relationship among Vibrio cholerae O1 El Tor strains causing the largest cholera epidemic in Kenya in the Late 1990s. J Clin Microbiol. 2006;44(9):3401-3404. https://doi.org/10.1128/JCM.00611-06

18. Sang WK, Oundo V, Schnabel D. Prevalence and antibiotic resistance of bacteria pathogens isolated from childhood diarrhoea in four provinces of Kenya. J Infect Dev Ctries. 2012;6(7):572-578. https://doi.org/10.3855/jidc.2196

19. Dromigny J-A, Rakoto-Alson O, Rajaonatahina D, Migliani R, Ranjalahy J, Mauclère P. Emergence and rapid spread of tetracycline resistant Vibrio cholerae strains, Madagascar. Emerg Infect Dis. 2002;8(3):336-338. https://doi.org/10.3201/ Madagascar. Em
eid0803.010258

20. Dengo-Baloi LC, Semá-Baltazar CA, Manhique LV, Chitio JE, Inguane DL, Langa JP. Antibiotics resistance in El Tor Vibrio cholerae 01 isolated during cholera outbreaks in Mozambique from 2012 to 2015. PLoS One. 2017;12(8):e0181496. https://doi. in Mozambique from 2012 to 2015.
org/10.1371/journal.pone.0181496

21. Smith AM, Keddy KH, Wee LD. Characterization of cholera outbreak isolates from Namibia, December 2006 to February 2007. Epidemiol Infect. 2008;136:12071209. https://doi.org/10.1017/S0950268807009685

22. Okeke IN, Abudu AB, Lamikanra A. Microbiological investigation of an outbreak of acute Gastroenteritis in Niger State, Nigeria. Clin Microbiol Infect. 2001;7:514516. https://doi.org/10.1046/j.1198-743x.2001.00281.x

23. Opajobi SO, Kandakai-Olukemi YT, Mawak JD, Olukemi MA, Bello CSS. Vibrio cholerae O1infections in Jos, Nigeria. Afr J Clin Exp Microbiol. 2004;5(3):260-264. https://doi.org/10.4314/ajcem.v5i3.7388
24. Quilici ML, Denis M, Bouba G, Barem B, David MO. Vibrio cholerae 01 variant with reduced susceptibility to ciprofloxacin, Western Africa. Emerg Infect Dis [seria online]. 2010 [cited 2017 Feb 17];16(11):1804-1805. Available from: www.cdc. gov/eid

25. Marin MA, Thompson CC, Freitas FS, et al. Cholera outbreaks in Nigeria are associated with multidrug resistant atypical El Tor and Non-O1/Non-O139 Vibrio cholerae. PLoS Neglected Trop Dis. 2013;7(2):e2049. https://doi.org/10.1371/ journal.pntd.0002049

26. Marin MA, Fonseca EL, Andrade BN, Cabral AC, Vicente ACP. Worldwide occurrence of integrative conjugative element encoding multidrug resistance determinants in epidemic Vibrio cholerae O1. PLoS One. 2014;9(9):e108728. https://doi.org/10.1371/journal.pone.0108728

27. Sjölund-Karlsson M, Reimer A, Folster JP, Walker M, Dahourou GA. Drug-resistance mechanisms in Vibrio cholerae O1 outbreak strain, Haiti, 2010. Emerg Infect Dis [serial online]. 2011 [cited 2017 Feb 06];17:2151-2154. Available from: http:// www.ncbi.nlm.nih.gov/pubmed/22141136

28. Wozniak RAF, Fouts DE, Spagnoletti M, Colombo MM, Ceccarelli D. Comparative ICE genomics: Insights into the evolution of the SXT/R391 family of ICEs. PLoS Genetics [serial online]. 2009 [cited $2017 \mathrm{Feb} 13$ ];5:e1000786. Available from http://www.pubmedcentral.nih.gov/articlerender.fcgi?artid=2791158\&tool=pmc entrez\&rendertype=abstract

29. Dutilh BE, Thompson CC, Vicente ACP, et al. Comparative genomics of 274 Vibrio cholerae genomes reveals mobile functions structuring three niche dimensions. BMC Genom. 2014;15(654):1-11. https://doi.org/10.1186/1471-2164-15-654

30. Sambe-Ba B, Diallo MH, Seck A, et al. Identification of Atypical El Tor Vibrio cholerae 01 Ogawa hosting SXT element in Senegal, Africa. Front Microbiol. 2017;8:748. https://doi.org/10.3389/fmicb.2017.00748

31. Ismail H, Smith AM, Sooka A, Keddy KH. Genetic characterization of multidrug resistant, extended-spectrum-lactamase-producing Vibrio cholerae 01 outbreak strains, Mpumalanga, South Africa, 2008. J Clin Microbiol. 2011;49(8):2976-2979. https://doi.org/10.1128/JCM.00293-11

32. Moyo SJ, Gro N, Matee MI, et al. Age specific aetiological agents of diarrhoea in hospitalized children aged less than five years in Dar es Salaam, Tanzania. BMC Pediatr [serial online]. 2011 [cited 2017 Jan 20];11:19. Available from: http:// www.biomedcentral.com/1471-2431/11/19

33. Mercy N, Mohamed AA, Zipporah N, et al. Phenotypic and genetic characterization of Vibrio cholera 01 isolated from various regions of Kenya between 2007 and 2010. Pan Afr Med J. 2014:19:8-16. https://doi.org/10.11604/pamj.2014.19.8.2496

34. Mwansa JCL, Mwabai J, Lukwesa C, et al. Multiply antibiotic-resistant Vibrio cholerae O1 biotype El Tor strains emerge during cholera outbreaks in Zambia. Epidemiol Infect. 2007;135:847-853. https://doi.org/10.1017/S0950268806007254

35. Chiyangi H, Muma JB, Malama S, Manyahi J, Abade A, Kwenda G. Identification and antimicrobial resistance patterns of bacterial enteropathogens from children aged 0-59 months at the University Teaching Hospital, Lusaka, Zambia: A prospective cross sectional study. BMC Infect Dis. 2017;17:117-125. https://doi. prospective cross sectional study.

36. Dalhat MM, Isa AN, Nguku P, et al. Descriptive characterization of the 2010 cholera outbreak in Nigeria. BMC Public Health. 2014;14:1167. https://doi. org/10.1186/1471-2458-14-1167

37. Okeke IN, Aboderin AO, Byarugaba DK, Ojo KK, Opintan J. Growing problem of multidrug-resistant enteric pathogens in Africa. Emerg Infect Dis [serial online]. 2007 [cited 2017 Feb 18];13:1640-1646. Available from: http://www.pubmedcentral.nih [cited 2017 Feb 18];13:1640-1646. Available from: http://www.pubmedcentral
gov/articlerender.fcgi?artid=3375797\&tool=pmcentrez\&rendertype=abstract

38. Siddique AK, Cash R. Cholera outbreaks in the classical biotype era. Curr Top Microbiol Immunol. 2014;379:1-16. https://doi.org/10.1007/82_2013_361

39. Karlsson SL, Ax E, Nygren E, et al. Development of stable Vibrio cholerae 01 Hikojima type vaccine strains co-expressing the Inaba and Ogawa Lipopolysaccharide Antigens. PLoS One [serial online]. 2014 [cited 2017 Feb 18];9(11). Available from: https://doi.org/10.1371/journal.pone.0108521

40. Lamikanra, A, Crowe JL, Lijek RS, et al. Rapid evolution of fluoroquinoloneresistant Escherichia coli in Nigeria is temporally associated with fluoroquinolone use. BMC Infect Dis. 2011;11:312. https://doi.org/10.1186/1471-2334-11-312

41. Martin S, Costa A, Perea W. Stockpiling oral cholera vaccine. Bull World Health Organ. 2012;90(10):714. https://doi.org/10.2471/BLT.12.112433

42. Chattaway MA, Aboderin AO, Fashae K, Okoro CK, Opintan JA, Okeke IN. Fluoroquinolone-resistant enteric bacteria in sub-Saharan Africa: Clones, implications and research needs. Front Microbiol. 2016;7:5. https://doi. org/10.3389/fmicb.2016.00558 